Received Date : 22-May-2016

Revised Date : 17-Jul-2016

Accepted Date : 18-Jul-2016

Article type : Original Manuscript

\title{
Candida virulence and ethanol-derived acetaldehyde production in oral cancer and non-cancer subjects
}

Ali D. Alnuaimi ${ }^{1}$,Adlin N. Ramdzan ${ }^{2}$, David Wiesenfeld ${ }^{1,3}$, Neil M. O’Brien-Simpson ${ }^{1}$, Spas D. Kolev ${ }^{2}$,Eric C. Reynolds ${ }^{1} \&$ Michael J. McCullough ${ }^{1, *}$

${ }^{1}$ Melbourne Dental School, Oral Health CRC, The University of Melbourne, Carlton, VIC 3053, Australia

${ }^{2}$ School of Chemistry, The University of Melbourne, Parkville, VIC 3010, Australia

${ }^{3}$ Head and Neck Oncology, The Royal Melbourne Hospital, Melbourne, Vic 3010, Australia
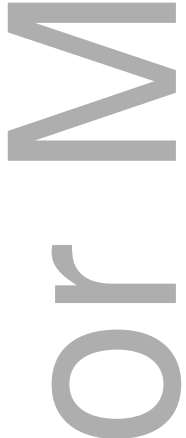

*Corresponding author. Tel.: +61 39341 1490; fax: +61 3 9341 1599; Email: m.mccullough@unimelb.edu.au

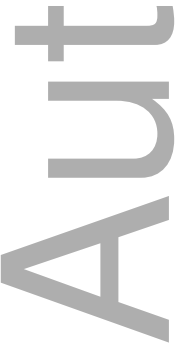

Running head: Candida virulence and oral cancer

This is the author manuscript accepted for publication and has undergone full peer review but has not been through the copyediting, typesetting, pagination and proofreading process, which may lead to differences between this version and the Version of Record. Please cite this article as doi: $10.1111 /$ odi.12565

This article is protected by copyright. All rights reserved 


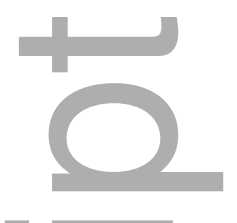

Key words: Oral cancer, Candida albicans, Microbial-induced carcinogenesis, Carcinogens, Acetaldehyde

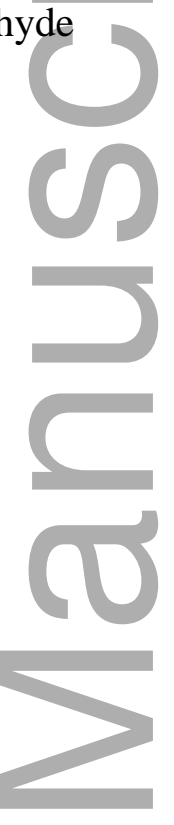

\section{Abstract}

Objectives: To compare biofilm-forming ability; hydrolytic enzymes and ethanol-derived acetaldehyde production of oral Candida isolated from the oral cancer and matched non-oral cancer patients.

Material and Methods: Fungal biofilms were grown in RPMI-1640 medium and biofilmmass and -activity were assessed using crystal-violet staining and XTT-salt reduction assays, respectively. Phospholipase, proteinase and esterase production was measured using agar plate method, while fungal acetaldehyde production was assessed via gas-chromatography.

Results: Candida isolated from oral cancer patients demonstrated significantly higher biofilm mass $(p=0.031)$, biofilm metabolic activity $(\mathrm{p}<0.001)$, phospholipase $(\mathrm{p}=0.002)$ and 
proteinase $(p=0.0159)$ activity than isolates from non-oral cancer patients. High ethanolderived acetaldehyde-producing Candida were more prevalent in oral cancer than non-oral cancer patients $(p=0.01)$. In univariate regression analysis high biofilm mass $(p=0.03)$ and metabolic activity $(\mathrm{p}<0.001)$, high phospholipase $(\mathrm{p}=0.003)$ and acetaldehyde production ability (0.01) were significant risk factors for oral cancer; while in the multivariate regression analysis high biofilm activity $(0.01)$ and phospholipase $(\mathrm{p}=0.01)$ were the only significantly positive influencing factors on oral cancer.

Conclusion: These data suggest a significant positive association between the ability of Candida isolates to form biofilms, to produce hydrolytic enzymes and to metabolize alcohol to acetaldehyde with their ability to promote oral cancer development.

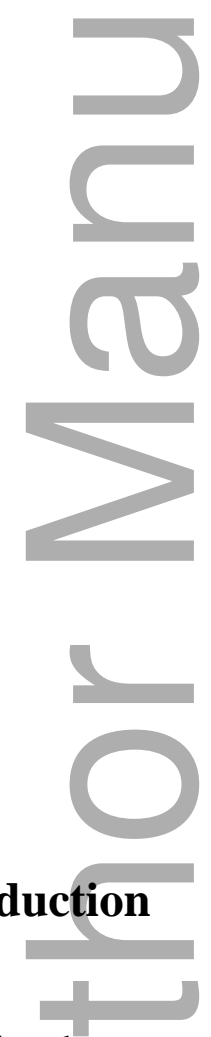

There has been cumulative clinical and laboratory evidence to support a putative role for oral yeasts in oral and oesophageal carcinoma (Field et al., 1989; Hooper et al., 2009). However, the underlying mechanisms linking Candida colonization/infection with oral squamous cell carcinoma remains contentious (Mohd Bakri et al., 2010). The apparent epidemiological links between microbial colonization/infection and cancer presence have indirectly implied an aetiological role for these microorganisms (McCullough et al., 2002) which has prompted the study of probable mechanisms by which microbial species may initiate or promote oral carcinogenesis. Apart from Candida's ability to produce direct carcinogens such as 
nitrosamine (Hooper et al., 2009), other mechanisms such as the induction of chronic inflammatory cytokines and the metabolism of ethanol to the carcinogenic acetaldehyde, may be involved in Candida-related oral carcinogenesis.

Evidence is building that chronic exposure to microorganisms and/or their products, such as endotoxins (lipopolysaccharides) and enzymes (e.g. proteases, collagenases, fibrinolysin, phospholipase), are toxic to host cells and may indirectly induce mutations or change signaling pathways that influence cell proliferation and/or survival of epithelial cells (Lax, 2005; Kurago et al., 2008). Candida biofilm forming ability and hydrolytic enzyme production are essential virulence factors that enable this fungus to survive many challenging oral conditions and to adhere to, or invade the underlying host tissues (Calderone and Fonzi, 2001; Ramage et al., 2012). Hence, the chronic mucosal/epithelial colonization by Candida with enhanced virulence properties may have a role in oral carcinogenesis.

Acetaldehyde $(\mathrm{ACH})$, the first metabolite of ethanol metabolism, has been found to facilitate the formation of mutagenic acetaldehyde DNA-adducts in clinically relevant concentrations (40- $100 \mu \mathrm{M}$ ) (Brooks and Theruvathu, 2005; Seitz and Stickel, 2007; Nieminen et al., 2009). Candida has been postulated to have a direct carcinogenic role through its ability to convert ethanol into carcinogenic acetaldehyde, which may explain the highly significant epidemiological association between oral Candida carriage, alcohol drinking and oral cancer presence reported in our previous investigation (Alnuaimi et al., 2015).

To date, no study has simultaneously examined the association between Candida virulence traits, its ability to metabolize alcohol to the carcinogen acetaldehyde and the presence of oral cancer. Therefore, this study mainly aimed to compare the in vitro biofilm forming ability, major hydrolytic enzyme (proteinase, phospholipase and esterase) and ethanol-derived acetaldehyde production of Candida yeasts previously isolated from oral cavities of oral cancer and matched non-oral cancer patients. The association of these fungal virulence factors with other patients' factors was also examined. Further, this study aimed to compare these virulence attributes in different Candida species and C. albicans genotypes. This might help to explore additional mechanisms through which this yeast may initiate/promote oral mucosal carcinogenesis.

\section{Methods}




\section{Organisms}

The organisms used in the present study were obtained from a larger case-control survey investigating oral Candida colonization in oral cancer patients and its association with other risk factors of oral cancer (Alnuaimi et al., 2015). Ethical approval was granted, as previously reported, and all patients gave informed consent prior to being enrolled in the present study (Alnuaimi et al., 2015). Of the 156 patients 52 oral cancer patients and 104 age ( \pm three years), gender and denture status (with or without denture) matched non-oral cancer patients), 80 patients had Candida growth in their oral cavity. Thirty six $(69.2 \%)$ of oral cancer patients and $44(42.3 \%)$ of non-oral cancer patients were found to be carriers for this yeast (Alnuaimi et al., 2015). CHROMagar Candida medium and real time PCR-high resolution melting curve analysis were used to characterize these isolates at the species and sub-species level (Alnuaimi et al.,2014). According to these methods, a total of eight Candida species and 90 strains were identified from both patients groups. The distribution of these isolates is presented in Table 1. At the subspecies level, only the species C. albicans was broadly genotyped via the $\mathrm{ABC}$ genotypic method based on the size and presence of transposable intron in the $25 \mathrm{~S}$ of ribosomal DNA into C. albicans genotype A, genotype B and genotype C (Table 1) (McCullough et al., 1999; Alnuaimi et al., 2014; Alnuaimi et al., 2015).

\section{Preparation of yeast suspension and biofilm growth}

Biofilms were prepared as previously described (Silva et al., 2010; Alnuaimi et al., 2013), except that yeasts cells were suspended in RPMI 1640 medium ( $\mathrm{pH}=7$ and $0.2 \%$ glucose) supplemented with L-glutamine and buffered with MOPS [3-( $N$-morpholino)propanesulfonic acid]; (Department of Microbiology and Immunology, Media preparation unit, The University of Melbourne, Australia). Experiments were carried out in triplicate on two separate occasions for each strain with uninoculated controls. Biofilm mass and metabolic activity was assessed using crystal violet and tetrazolium salt reduction assays, respectively, and as previously described (Silva et al., 2010; Alnuaimi et al., 2013).

\section{Hydrolytic enzymes production assay}

Enzymatic activities of all Candida isolates were tested in triplicate using the agar plate method (Price et al., 1982; Treviño-Rangel Rde et al., 2013). All test media were prepared at the Department of Microbiology and Immunology, Media preparation unit, The University of Melbourne, Australia. 
Aspartyl proteinase activity was assayed using YCB-BSA test medium which was prepared according to previously published protocol (Chakrabarti et al., 1991). Phospholipase activity was evaluated using the egg yolk agar plate (Ghannoum, 2000); while esterase activity was determined using the tween 80 opacity test medium (Slifkin, 2000; Kumar etal., 2006).

A single drop $(5 \mu \mathrm{L})$ of un-inoculated RPMI medium and three separate drops $(5 \mu \mathrm{L}$ each) of RPMI 1640 medium containing overnight Candida growth at concentration of $1 \mathrm{x}$ $10^{7} \mathrm{cfu} / \mathrm{mL}$ were spotted carefully to outer quadrants of plate containing the specific agar medium. The plates were incubated at $37^{\circ} \mathrm{C}$ for 5 days for aspartyl proteinase and phospholipase assays and for 10 days for esterase assay. After incubation period, the plates were inspected for zones of degradation and/or precipitation around the yeast colonies. Results were expressed as: (colony diameter plus the precipitation halo/the colony diameter)1. According to this formula, a zero value indicates no activity (no increase in the total diameter of colony and precipitation zone), while a value above zero means a positive enzymatic activity.

\section{Ethanol-derived acetaldehyde production assay}

The methods used herein for ethanol-derived acetaldehyde production are similar to those reported earlier by Nieminen et al. (2009) and Gainza-Cirauqui et al. (2013) (Nieminen et al., 2009; Gainza-Cirauqui et al., 2013). Yeasts cells were suspended in phosphate buffered saline (PBS) at a final density of $1 \times 10^{7}$ cells $/ \mathrm{mL}$ via a haemocytometer. Five hundred microliters of this cells suspension was transferred into gas chromatography vials (Grace, Victoria, Australia) containing $500 \mu \mathrm{L}$ of ethanol at final concentration of $11 \mathrm{mM}$. The vials were immediately closed with screw caps (Grace, Victoria, Australia) and incubated, aerobically, at $37^{\circ} \mathrm{C}$ for 30 minutes. Subsequently, the reaction was stopped by injecting 100 $\mu \mathrm{L}$ of Perchloric acid (Sigma-Aldrich, NSW, Australia) at final concentration of (0.6 M) through the silicone septum of the test vials. Every isolate was tested in triplicate on two separate occasions and the mean was used for analysis. To measure the baseline ACH, 100 $\mu \mathrm{L}$ of Perchloric acid was first added to the yeast suspension $(500 \mu \mathrm{L})$ and ethanol $(500 \mu \mathrm{L})$ was injected afterward. Subsequently, the suspension was incubated at $37^{\circ} \mathrm{C}$ for 30 minutes. The ACH formed was measured by a gas chromatograph (GC; GC-2010, Shimadzu Co., Kyoto, Japan) as previously described (Ramdzan et al., 2013). Acetaldehyde concentration 
was calculated by subtracting values of control samples from that of actual yeast samples. The concentration of ethanol used in the present study is considered clinically pertinent, as it can be detected in blood and saliva following moderate alcohol consumption (Nieminen et al., 2009).

\section{Statistical analysis}

Data were analysed by using SPSS (PASW Statistics GradPack 18 Inc., USA) and GraphPad Prism 6 softwares (GraphPad software Inc., USA). The distribution of data for biofilm formation, hydrolytic enzymes and acetaldehyde for these isolates failed the Shapiro-Wilks test of normal distribution ( $\mathrm{p}<0.05$ ). Therefore, data were analysed using Mann -Whitney test and the association between Candida virulence attributes and different patients' factors (oral cancer presence, medical problems, gender, smoking, alcohol drinking, alcohol-containing mouthwash use, level of Candida colonization, presence of periodontal disease and denture use) was evaluated using Chi square or Fisher's exact tests. Detailed patients' factors such as smoking, drinking habits, tumor site and others can be found in our recent investigation (Alnuaimi et al.,2015) and the association between these patients' factors and Candida virulence attributes can be found in table 2. Logistic Regression model for oral cancer presence, with Candida virulence factors and colonization, smoking and alcohol drinking as explanatory variables, was performed as well. For biofilm formation and hydrolytic enzyme, the median was used to divide the isolates into high and low biofilm or hydrolytic enzyme producers. For the acetaldehyde production, a cut-off point of $40 \mu \mathrm{M}$ (Brooks and Theruvathu, 2005; Seitz and Stickel, 2007; Nieminen et al., 2009) was chosen to divide the isolates into high or low acetaldehyde producers. There was a mean of $567 \mathrm{cfu} / \mathrm{mL}$ obtained from all Candida isolates carriers and this was used as "internal cut-off" limit to assess the degree of candidal colonization amongst different patients (Alnuaimi et al., 2015). In patients colonized by more than one Candida species or strain, only the isolates with the highest virulence value was considered as a measure of yeast virulence in those patients. Two-sided $\mathrm{P}$ less than 0.05 was considered statistically significant.

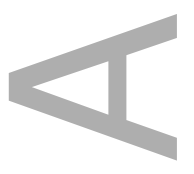




\section{Results}

\section{Biofilm formation}

Analysis of all 90 Candida isolates showed that the median biofilm mass and biofilm metabolic activity/biofilm was 1.86 and 0.38 , respectively. The frequency of high biofilm mass (CV absorbance > 1.86) and high biofilm metabolic activity (XTT absorbance > 0.38) was significantly $(\mathrm{p}=0.031, \mathrm{p}=0.0001$, respectively) higher amongst isolates from oral cancer patients $[\mathrm{n}=25 / 36,(69 \%), \mathrm{n}=28 / 36,(77.7 \%)$, respectively] than non-oral cancer patients' isolates $[n=20 / 44,(45.4 \%), n=14 / 44,(31.8 \%)$, respectively] (Table 2). However, MannWhitney test analysis showed that only biofilm metabolic activity was significantly $(\mathrm{p}<0.0001)$ higher in the oral cancer than the non-oral cancer patients' isolates (Figure 1B) and the difference was not significant in biofilm mass (Figure 1A).

Significant inter-species variation was observed in biofilm mass and metabolic activity with significantly higher frequency of high biofilm mass and metabolic activity $(\mathrm{p}<0.0001$, $\mathrm{p}=0.002$, respectively) seen in isolates from $C$. albicans species $[\mathrm{n}=42 / 63,(66.6 \%), \mathrm{n}=39 / 63$, (61.9\%), respectively] versus non-albicans Candida species [n=4/27, (14.8\%), n=7/27, (25.9\%), respectively] (Table 2$)$. Absence of denture was significantly ( $\mathrm{p}=0.048)$ associated with high biofilm mass; whereas smoking and the absence of periodontal disease were significantly ( $\mathrm{p}=0.019, \mathrm{P}=0.044$, respectively) associated with high biofilm metabolic activity (Table 2).

At C. albicans species level, comparing biofilm formation of $C$. albicans isolates from the two patient's cohorts indicated significantly $(\mathrm{p}<0.0001)$ higher biofilm metabolic activity in the oral cancer than non-oral cancer $C$. albicans isolates (Figure 2B). No significant difference was found in biofilm mass of this species in both patients groups (Figure 2A).

At the subspecies level, the median biofilm mass and metabolic activity/biofilm for $C$. albicans isolates was 2 and 0.4, respectively. Dividing C. albicans isolates into high and low biofilm mass and metabolic activity producers revealed no significant association between biofilm formation and C. albicans genotype (Table 2). However, analysis by Mann-Whitney test showed a significantly ( $\mathrm{p}=0.014$ ) higher biofilm mass for $C$. albicans genotype A than $C$. albicans genotype $\mathrm{B}$, with no significant difference seen in biofilm metabolic activity between the two genotypes (Figure 3A and 3B). 


\section{Hydrolytic enzyme production}

In a similar categorization fashion to that of biofilm formation, all 90 Candida isolates were divided into high and low hydrolytic enzyme producers according to the median proteinase activity, median phospholipase activity and median esterase activity (1.4, 0.8 and 0.88 , respectively). The frequency of high phospholipase producers was significantly $(p=0.002)$ higher in the oral cancer $[n=27 / 36,(75 \%)]$ than the non-oral cancer isolates $[n=18 / 44,(40 \%)]$ (Table 2). This was supported by Mann-Whitney analysis where Candida isolates form oral cancer patients expressed higher $(\mathrm{p}=0.005)$ phospholipase level than those from non-oral cancer patients (Figure 1D). Whereas no significant difference was revealed by MannWhitney analysis in the expression of proteinase and esterase enzymes between oral cancer and non-oral cancer patients' isolates (Figure $1 \mathrm{C}$ and 1E, respectively). There was a significant $(\mathrm{p}=0.001)$ association between high esterase activity and the absence of periodontal disease. No other differences $(p>0.05)$ were observed in hydrolytic enzyme production of isolates from any of the 80 Candida carriers evaluated in this study (Table 2).

Significant inter- and intra-species differences were also observed in the level of hydrolytic enzyme production with significantly higher number of high phospholipase and esterase enzyme producers $(\mathrm{p}<0.0001, \mathrm{p}=0.011$, respectively) seen in $C$. albicans isolates [n=46/63, (73\%), n=37/63, (58.7\%), respectively] versus non-albicans Candida isolates $[\mathrm{n}=8 / 27,(29.6 \%), \mathrm{n}=8 / 27,(42.1 \%)$, respectively] and significantly $(\mathrm{P}=0.038)$ higher number of high proteinase producers was observed in the non-albicans Candida isolates $[\mathrm{n}=18 / 27$, $(66.6 \%)$ ] versus C. albicans isolates [n=27/63, (42.8\%)] (Table 2).

At C. albicans species level, Mann-Whitney analysis showed significantly $(\mathrm{p}=0.015)$ higher proteinase activity in $C$. albicans isolates from oral cancer patients than those from non-oral cancer patients and significantly $(\mathrm{p}=0.042)$ higher esterase activity in isolates from non-oral cancer patients than those from oral cancer patients (Figures $2 \mathrm{C}$ and $2 \mathrm{E}$ ). No difference was observed in phospholipase enzyme production by $C$. albicans isolates from the two patient groups (Figure 2D). At the sub-species level, the median proteinase, phospholipase and esterase actvitiy for $C$. albicans isolates was 1.2, 0.91 and 1, respectively. According to these median values, there was no significant difference in the in vitro 
expression of these enzymes between $C$. albicans genotypes by chi square or Mann-Whiteny analysis (Table 2 and figures 3C, 3D and 3E).

\section{Ethanol-derived acetaldehyde production capability}

A total of $34 / 80(42.5 \%)$ patients were colonized by Candida isolates that were able to produce a mutagenic level of ACH from yeast incubation with $11 \mathrm{mM}$ of ethanol (Table 2). The percentage of Candida isolates with high acetaldehyde producing ability ( $>40 \mu \mathrm{M})$ was significantly $(\mathrm{p}=0.01)$ higher amongst oral cancer $[\mathrm{n}=21 / 36,(58 \%)]$ than non-oral cancer patients [n=13/44, (29.5\%)] (Table 2). Mann-Whitney analysis also indicated significantly $(\mathrm{p}=0.032)$ higher amount of acetaldehyde produced by isolates from oral cancer patients compared to those from non-oral cancer patients (Figure 1F). The frequency of Candida isolates that produced high levels of $\mathrm{ACH}$ was higher $(\mathrm{p}=0.037)$ in patients with high Candida colonization level (> $567 \mathrm{CFU}$ ) than those with low colonization level (<567 CFU) (Table 2). No significant association was found between the ability of Candida to produce acetaldehyde and all other patients' factors.

Differences amongst Candida species and strains were also observed in the amount of $\mathrm{ACH}$ produced. Although the frequency of high $\mathrm{ACH}$ production was higher in C. albicans isolates than the non-albicans Candida isolates, this did not reach the level of statistical significance $(\mathrm{p}=0.088)$ (Table 2$)$.

Comparing $\mathrm{ACH}$ production of $C$. albicans isolates only, isolates from oral cancer patients produced significantly $(\mathrm{p}=0.039)$ higher amount of $\mathrm{ACH}$ than those from non-oral cancer patients (Figure 2F). No significant association was seen between ACH production and $C$. albicans genotype and there was no difference in $\mathrm{ACH}$ production between $C$. albicans genotype A and genotype B (Table 2) (Figure 3F).

\section{The risk effect of Candida virulence and ethanol-derived $\mathrm{ACH}$ on oral cancer}

The univariate and multivariate logistic regression analyses are presented in Table 3 . In the univariate analysis high Candida biofilm mass and metabolic activity, high phospholipase enzyme activity, high ethanol-derived ACH production, current/daily alcohol drinking and high Candida colonization were significant risk factors for oral cancer. However, in the multivariate analysis, high biofilm metabolic activity and phospholipase enzyme production, and alcohol drinking were the only significantly positive influencing factors on oral cancer 
risk. Although Candida yeasts with high biofilm mass, proteinase and high acetaldehyde production capability did not show a significant risk in the multivariate analysis; the likelihood of cancer presence was higher (odds ratio higher than 1) in patients colonized by these isolates than those colonized by isolates with low virulence (Table 3).

\section{Discussion}

The present study is the first to demonstrate a clear association between virulence attributes and ethanol-derived acetaldehyde production capability of Candida yeasts and oral cancer. Isolates from oral cancer patients exhibited a higher capacity to form biofilms, to produce phospholipase and proteinase enzymes and to metabolize alcohol to acetaldehyde. Further, the multivariate logistic regression analysis showed that Candida high biofilm metabolic activity, high phospholipase enzyme activity and high oral Candida colonization level were significant risk factors for oral cancer. While the present study has supplied much useful information about virulence properties of yeasts isolated from oral cancer patients, it has some limitations that must be acknowledged. Firstly, it is important to emphasize the fact that due to the design of the present study (case-controls), the results only give information regarding associations, without a cause-effect relationship. Nonetheless, these data may have clinical and pathological significance as individuals may have chronic oral colonization by yeast isolates that simultaneously have enhanced pathogenic properties, such as biofilm formation, hydrolytic enzyme and ethanol-derived acetaldehyde production capacity. Such chronic colonization could play a role in the promotion of oral premalignant and malignant lesions. High biofilm forming ability is likely to secure a prolonged oral colonization and chronic exposure of host tissues to fungal carcinogens, such as acetaldehyde; while enhanced hydrolytic enzyme production may allow for progressive tissue destruction promoting a chronic inflammatory response.

The chronic microbial irritation may result in a chronic inflammatory response and subsequent release of cascade of cytokines and chemokines that infiltrate disrupted and damaged tissues. Studies have shown a significant positive correlation between virulence potential of pathogenic fungi, such as secreted aspartyl proteinases, and the expression of inflammatory cytokines and chemokines (Beausejour et al., 1998; Schaller et al., 2002; Schaller et al., 2005). It has been postulated that chronic inflammation caused by microbial infection is a major driving force in tumour development and indispensable participant in the neoplastic process (Karin and Greten, 2005). Given the current findings of enhanced 
virulence potential of Candida isolated from oral cancer patients and the previously reported positive correlation between Candida virulence and cytokine expression (Beausejour et al., 1998; Schaller et al., 2002; Schaller et al., 2005), it could be surmised that pro-carcinogenesis inflammation is a working hypotheses behind the strong epidemiological association between oral Candida colonization and oral cancer presence (Alnuaimi et al., 2015). However, another limitation of our study which could be an objective of further research is that we did not investigate the correlation between the severity of inflammatory changes at cancerous sites and virulence of Candida isolated from these sites.

Previous studies (Ghannoum, 2000; Parahitiyawa et al., 2006; Silva et al., 2010; Sardi et al., 2013) showed that significant variation exists in biofilm mass, biofilm metabolic activity, phospholipase activity, proteinase activity and esterase activity between different Candida species. In the present study, $C$. albicans isolates produced higher levels of these virulence-associated traits, confirming the high virulence potential of this species when compared to other Candida species. Interestingly, in this study, non-albicans Candida species had significantly greater proteinase activity.

Previous studies have demonstrated a significant association between $\mathrm{ABC}$ genotyping and the virulence potential of C. albicans strains (Qianming et al., 2004; Zeng et al., 2008; Sardi et al., 2012). In our previous investigation, a significant epidemiological relationship was found between oral cancer presence and C. albicans genotype (Alnuaimi et al., 2015). Specifically, a significantly higher frequency of genotype A was observed in C. albicans strains isolated from oral cancer patients and significantly higher frequency of genotype B was seen in non-oral cancer patients. This called for investigating whether this genotypic variation would have any pathogenic or carcinogenic implication. However, consistent with other reports (Manfredi et al., 2006; Mane et al., 2012), a relationship could not be established between genotype and any of the investigated virulence factors other than significantly higher biofilm mass was obtained by genotype A than genotype B isolates. This highlights the need for investigating further genetic linkages, and perhaps, using more discriminatory molecular genotyping methods such as multilocus sequence typing (MLST) analysis that could help dissect the molecular basis for this preferential strain selection.

Alcohol, tobacco smoking and poor oral hygiene are the most significant environmental risk factors for upper aerodigestive tract cancers (Boffetta and Hashibe, 2006; Pelucchi et al., 2008). Alcohol itself is not carcinogenic, but the increased risk of oral and upper digestive tract cancers in high alcohol consumers has been linked to the increased local level of $\mathrm{ACH}$, particularly amongst those with poor oral hygiene (Homann et al., 2000a; 
Homann et al., 2000b). Acetaldehyde is metabolized from ethanol by alcohol dehydrogenases (ADH) from oral mucosal epithelial cells and from oral microbiota (Hooper et al., 2009). Several oral bacteria such as Neisseria and Streptococci species have been associated with marked ADH enzyme activity resulting in high acetaldehyde production (Muto et al., 2000; Kurkivuori et al., 2007). The same has also been reported for some yeast species (Tillonen et al., 1999; Salaspuro, 2003). One of the most significant hypotheses on how Candida may be associated with oral cancer development relates to its well-documented ability to produce acetaldehyde from ethanol by oxidation. (Mohd Bakri et al., 2010). There are few comparative studies that have been conducted regarding the level of $\mathrm{ACH}$ produced by Candida isolated from patients with precancerous and cancerous lesions versus isolates from healthy patients (Gainza-Cirauqui et al., 2013; Marttila et al., 2013). However, these studies have not examined the inter- and intra-species variation in $\mathrm{ACH}$ production or their data were not derived from matched case-control study design. In addition, researchers have not simultaneously examined ACH production and other Candida virulence attributes. One such study showed no significant difference in ACH production between Candida isolated from oral cancer and healthy patients (Marttila et al., 2013); while the other, interestingly, showed higher level of $\mathrm{ACH}$ in the healthy control patients (Gainza-Cirauqui et al., 2013). In the present study, a significantly higher level of ACH was produced by Candida isolated from oral cancer patients compared with matched non-oral cancer patients, suggesting a significant association between the ability of isolates to produce acetaldehyde and to promote cancer development. This may also partly explain the highest cancer risk, observed in our previous investigation, when Candida presence was conjugated with alcohol drinking (Alnuaimi et al., 2015).

\section{Conclusions}

These data support the concept of preferential selection of Candida isolates with enhanced virulence properties and carcinogenic acetaldehyde production in oral cancer-affected individuals. These data also suggest a significant positive association between the ability of Candida isolates to form biofilms, to produce hydrolytic enzymes and to metabolize alcohol to acetaldehyde with their ability to promote oral cancer development. Thorough understanding of the biological behaviour of yeasts associated with oral cancer will be useful in assessment of their role in oral mucosal carcinogenesis and may lead to significant 
advances in our understanding of oral cancer aetiology, potentially opening up new approaches for therapeutic intervention. Controlled prospective studies are necessary to continue exploring the potential association between Candida and oral cancer. Further, indepth, studies using more complex setting resembling in vivo conditions are warranted to elucidate the interaction of Candida with oral mucosal cells at a molecular level to broaden our understanding of the relationship of yeasts to oral cancer risk.

므
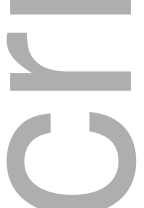

\section{Acknowledgement}

This work was funded by a grant from Oral Health CRC (Cooperative Research Centre) of Melbourne Dental School, The University of Melbourne.

Conflicts of interest: Non to declare.

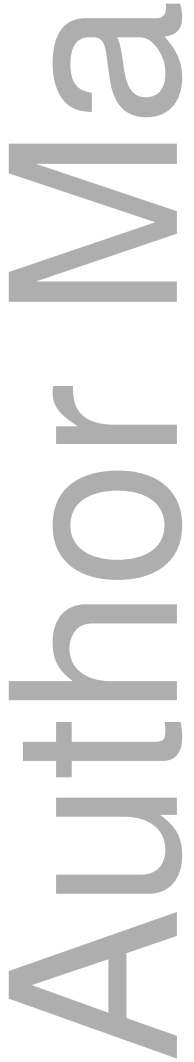




\section{$\overline{0}$ \\ . \\ . \\ References}

Alnuaimi AD, O'Brien-Simpson NM, Reynolds EC,McCullough MJ (2013). Clinical isolates and laboratory reference Candida species and strains have varying abilities to form biofilms. FEMS Yeast Res, 13, 689-699.

Alnuaimi AD, Wiesenfeld D, O'Brien-Simpson NM, Reynolds EC, Peng B,McCullough MJ (2014). The development and validation of a rapid genetic method for species identification and genotyping of medically important fungal pathogens using high resolution melting curve analysis. Mol Oral Microbiol, 29, 117-130.

Alnuaimi AD, Wiesenfeld D, O'Brien-Simpson NM, Reynolds EC,McCullough MJ (2015). Oral Candida colonization in oral cancer patients and its relationship with traditional risk factors of oral cancer: A matched case-control study. Oral Oncol, 51, 139-145.

Beausejour A, Grenier D, Goulet JP,Deslauriers N (1998). Proteolytic activation of the interleukin-1beta precursor by Candida albicans. Infect Immun, 66, 676-681.

Boffetta P,Hashibe M (2006). Alcohol and cancer. Lancet Oncol, 7, 149-156.

Brooks PJ,Theruvathu JA (2005). DNA adducts from acetaldehyde: implications for alcoholrelated carcinogenesis. Alcohol, 35, 187-193.

Calderone RA,Fonzi WA (2001). Virulence factors of Candida albicans. Trends Microbiol, 9, 327-335.

Chakrabarti A, Nayak N,Talwar P (1991). In vitro proteinase production by Candida species. Mycopathologia, 114, 163-168. 
Field EA, Field JK,Martin MV (1989). Does Candida have a role in oral epithelial neoplasia? J Med Vet Mycol, 27, 277-294.

Gainza-Cirauqui ML, Nieminen MT, Novak Frazer L, Aguirre-Urizar JM, Moragues MD,Rautemaa R (2013). Production of carcinogenic acetaldehyde by Candida albicans from patients with potentially malignant oral mucosal disorders. J Oral Pathol Med, 42, 243-249.

Ghannoum MA (2000). Potential role of phospholipases in virulence and fungal pathogenesis. Clin Microbiol Rev, 13, 122-143.

Homann N, Tillonen J, Meurman JH, Rintamaki H, Lindqvist C, Rautio M, Jousimies-Somer H,Salaspuro M (2000a). Increased salivary acetaldehyde levels in heavy drinkers and smokers: a microbiological approach to oral cavity cancer. Carcinogenesis, 21, 663668.

Homann N, Tillonen J,Salaspuro M (2000b). Microbially produced acetaldehyde from ethanol may increase the risk of colon cancer via folate deficiency. Int J Cancer, 86, 169-173.

Hooper SJ, Wilson MJ,Crean SJ (2009). Exploring the link between microorganisms and oral cancer: a systematic review of the literature. Head Neck, 31, 1228-1239.

Karin M,Greten FR (2005). NF-kappaB: linking inflammation and immunity to cancer development and progression. Nat Rev Immunol, 5, 749-759.

Kumar CP, Menon T, Sundararajan T, Nalini S, Thirunarayan MA, Rajasekaran S,Venkatadesikalu M (2006). Esterase activity of Candida species isolated from immunocompromised hosts. Rev Iberoam Micol, 23, 101-103.

Kurago ZB, Lam-ubol A, Stetsenko A, De La Mater C, Chen Y,Dawson DV (2008). Lipopolysaccharide-squamous cell carcinoma-monocyte interactions induce cancersupporting factors leading to rapid STAT3 activation. Head Neck Pathol, 2, 1-12.

Kurkivuori J, Salaspuro V, Kaihovaara P, Kari K, Rautemaa R, Grönroos L, Meurman JH,Salaspuro M (2007). Acetyldehyde production from ethanol from by oral streptococci. Oral Oncol, 43, 181-186.

Lax AJ (2005). Opinion: Bacterial toxins and cancer--a case to answer? Nat Rev Microbiol, 3, 343-349.

Mane A, Gaikwad S, Bembalkar S,Risbud A (2012). Increased expression of virulence attributes in oral Candida albicans isolates from human immunodeficiency viruspositive individuals. J Med Microbiol, 61, 285-290. 
Manfredi M, McCullough MJ, Al-Karaawi ZM, Vescovi P,Porter SR (2006). In vitro evaluation of virulence attributes of Candida spp. isolated from patients affected by diabetes mellitus. Oral Microbiol Immunol, 21, 183-189.

Marttila E, Uittamo J, Rusanen P, Lindqvist C, Salaspuro M,Rautemaa R (2013). Acetaldehyde production and microbial colonization in oral squamous cell carcinoma and oral lichenoid disease. Oral Surg Oral Med Oral Pathol Oral Radiol, 116, 61-68.

McCullough MJ, Clemons KV,Stevens DA (1999). Molecular and phenotypic characterization of genotypic Candida albicans subgroups and comparison with Candida dubliniensis and Candida stellatoidea. J Clin Microbiol, 37, 417-421.

McCullough M, Jaber M, Barrett AW, Bain L, Speight PM,Porter SR (2002). Oral yeast carriage correlates with presence of oral epithelial dysplasia. Oral Oncol, 38, 391393.

Mohd Bakri M, Mohd Hussaini H, Rachel Holmes A, David Cannon R,Mary Rich A (2010). Revisiting the association between candidal infection and carcinoma, particularly oral squamous cell carcinoma. J Oral Microbiol, 2, doi: 10.3402/jom.v2i0.5780.

Muto M, Hitomi Y, Ohtsu A, Shimada H, Kashiwase Y, Sasaki H, Yoshida S,Esumi H (2000). Acetaldehyde production by non-pathogenic Neisseria in human oral microflora: implications for carcinogenesis in upper aerodigestive tract. Int J Cancer, $88,342-350$.

Nieminen MT, Uittamo J, Salaspuro M,Rautemaa R (2009). Acetaldehyde production from ethanol and glucose by non-Candida albicans yeasts in vitro. Oral Oncol, 45, e245248.

Parahitiyawa NB, Samaranayake YH, Samaranayake LP, Ye J, Tsang PW, Cheung BP, Yau JY,Yeung SK (2006). Interspecies variation in Candida biofilm formation studied using the Calgary biofilm device. APMIS., 114, 298-306.

Pelucchi C, Gallus S, Garavello W, Bosetti C,La VC (2008). Alcohol and tobacco use, and cancer risk for upper aerodigestive tract and liver. Eur J Cancer Prev, 17, 340-344.

Price MF, Wilkinson ID,Gentry LO (1982). Plate method for detection of phospholipase activity in Candida albicans. Sabouraudia, 20, 7-14.

Qianming C, Xin Z, Li. B,Min Z (2004). The genotypic profiles of Candida albicans isolates from patients with oral leukoplakia and oral squamous cell carcinoma and the correlation with their virulence attribute. Cancer Res, 45, 109.

Ramage G, Rajendran R, Sherry L,Williams C (2012). Fungal biofilm resistance. Int J Microbiol, 2012, 528521. 
Ramdzan AN, Mornane PJ, McCullough MJ, Mazurek W,Kolev SD (2013). Determination of acetaldehyde in saliva by gas-diffusion flow injection analysis. Anal Chim Acta, 786, 70-77.

Salaspuro MP (2003). Acetyldehyde, microbes and cancer of the digestive tract. Crit Rev Clin Lab Sci, 40, 183-208.

Sardi JC, Duque C, Höfling JF,Gonçalves RB (2012). Genetic and phenotypic evaluation of Candida albicans strains isolated from subgingival biofilm of diabetic patients with chronic periodontitis. Med Mycol., 50, 467-475.

Sardi JC, Scorzoni L, Bernardi T, Fusco-Almeida AM,Mendes Giannini MJ (2013). Candida species: current epidemiology, pathogenicity, biofilm formation, natural antifungal products and new therapeutic options. J Med Microbiol, 62, 10-24.

Schaller M, Mailhammer R, Grassl G, Sander CA, Hube B,Korting HC (2002). Infection of human oral epithelia with Candida species induces cytokine expression correlated to the degree of virulence. J Invest Dermatol, 118, 652-657.

Schaller M, Korting HC, Borelli C, Hamm G,Hube B (2005). Candida albicans-secreted aspartic proteinases modify the epithelial cytokine response in an in vitro model of vaginal candidiasis. Infect Immun, 73, 2758-2765.

Seitz HK,Stickel F (2007). Molecular mechanisms of alcohol-mediated carcinogenesis. Nat Rev Cancer, 7, 599-612.

Silva S, Henriques M, Oliveira R, Williams D,Azeredo J (2010). In vitro biofilm activity of non-Candida albicans Candida species. Curr Microbiol, 61, 534-540.

Slifkin M (2000). Tween 80 opacity test responses of various Candida species. J Clin Microbiol, 38, 4626-4628.

Tillonen J, Homann N, Rautio M, Jousimies-Somer H,Salaspuro M (1999). Role of yeasts in the salivary acetaldehyde production from ethanol among risk groups for ethanolassociated oral cavity cancer. Alcohol Clin Exp Res, 23, 1409-1415.

Treviño-Rangel Rde J, González JG,González GM (2013). Aspartyl proteinase, phospholipase, esterase and hemolysin activities of clinical isolates of the Candida parapsilosis species complex. Med Mycol, 51, 331-335.

Zeng X, Xiong C, Wang Z, Jiang L, Hou X, Shen J, Zhou M,Chen Q (2008). Genotypic profiles and virulence attributes of Candida albicans isolates from patients with oral lichen planus. APMIS, 116, 284-291. 
Table 1: Candida species/strain distribution in oral cancer and non-oral cancer patients (Alnuaimi et al., 2015).

\begin{tabular}{|c|c|c|}
\hline & \multicolumn{2}{|c|}{ Patients } \\
\hline Candida species/strains & Oral cancer & Non-oral cancer \\
\hline C. albicans & $31(79.5 \%)$ & $32(62.75 \%)$ \\
\hline Genotyp & $27(69.23 \%)$ & $15(29.41 \%)$ \\
\hline Genotyp & $4 \quad(10.25 \%)$ & $16(31.37 \%)$ \\
\hline Genotype C & $0 \quad(0 \%)$ & $1(1.96 \%)$ \\
\hline C. dubliniensi & $3(7.7 \%)$ & $3(5.88 \%)$ \\
\hline C. glabrata & $2(5.12 \%)$ & $3(5.88 \%)$ \\
\hline C. parapsilos & $0 \quad(0 \%)$ & $9(17.65 \%)$ \\
\hline C. krusei & $1(2.56 \%)$ & $0 \quad(0 \%)$ \\
\hline C. tropicalis & $0 \quad(0 \%)$ & $3(5.88 \%)$ \\
\hline C. lusitaniae & $0 \quad(0 \%)$ & $1(1.96 \%)$ \\
\hline C. guilliermondii & $2(5.12 \%)$ & $0 \quad(0 \%)$ \\
\hline Total & $39(100 \%)$ & $51(100 \%)$ \\
\hline
\end{tabular}




\begin{tabular}{|c|c|c|c|c|c|c|c|c|c|c|c|c|c|c|c|c|c|}
\hline $\begin{array}{l}\text { Biofilm } \\
\text { mass } \\
\text { above } \\
\text { the } \\
\text { median }\end{array}$ & $\begin{array}{l}\text { Biofilm } \\
\text { mass } \\
\text { below } \\
\text { the } \\
\text { median }\end{array}$ & $\begin{array}{l}\mathrm{P}^{\mathrm{e}} \\
\text { value }\end{array}$ & $\begin{array}{l}\text { Biofilm } \\
\text { activity } \\
\text { above } \\
\text { the } \\
\text { median }\end{array}$ & $\begin{array}{l}\text { Biofilm } \\
\text { activity } \\
\text { below } \\
\text { the } \\
\text { median }\end{array}$ & $\begin{array}{l}\mathrm{P}^{\mathrm{e}} \\
\text { value }\end{array}$ & $\begin{array}{l}\mathrm{IP}^{\mathrm{a}} \\
\text { above } \\
\text { the } \\
\text { median }\end{array}$ & $\begin{array}{l}\mathrm{IP}^{\mathrm{a}} \\
\text { below } \\
\text { the } \\
\text { median }\end{array}$ & $\begin{array}{l}\mathrm{P}^{\mathrm{e}} \\
\text { value }\end{array}$ & $\begin{array}{l}\mathrm{IPL}^{\mathrm{b}} \\
\text { above } \\
\text { the } \\
\text { median }\end{array}$ & $\begin{array}{l}\text { IPL }^{b} \\
\text { below } \\
\text { the } \\
\text { median }\end{array}$ & $\begin{array}{l}\mathrm{P}^{\mathrm{e}} \\
\text { value }\end{array}$ & $\begin{array}{l}\mathrm{IE}^{\mathrm{c}} \\
\text { above } \\
\text { the } \\
\text { median }\end{array}$ & $\begin{array}{l}\mathrm{IE}^{\mathrm{c}} \\
\text { below } \\
\text { the } \\
\text { median }\end{array}$ & $\begin{array}{l}\mathrm{P}^{\mathrm{e}} \\
\text { Value }\end{array}$ & $\begin{array}{l}\mathrm{ACH}^{\mathrm{d}} \\
\text { Above } \\
40 \mu \mathrm{M}\end{array}$ & $\begin{array}{l}\mathrm{ACH}^{\mathrm{d}} \\
\text { below } \\
40 \mu \mathrm{M}\end{array}$ & $\begin{array}{l}\mathrm{P}^{\mathrm{e}} \\
\text { value }\end{array}$ \\
\hline 25 & 11 & $\mathbf{0 . 0 3 1}$ & 28 & 8 & $<0.0001$ & 23 & 13 & 0.1 & 27 & 9 & 0.002 & 16 & 20 & 0.271 & 21 & 15 & 0.01 \\
\hline No cancer & 24 & & 14 & 30 & & 20 & 24 & & 18 & 26 & & 25 & 19 & & 13 & 31 & \\
\hline Medical problems & 21 & 0.684 & 23 & 27 & 0.133 & 25 & 25 & 0.385 & 26 & 24 & 0.323 & 27 & 23 & 0.525 & 22 & 28 & 0.726 \\
\hline No medical problems $\quad 16$ & 14 & & 19 & 11 & & 18 & 12 & & 19 & 11 & & 14 & 16 & & 12 & 18 & \\
\hline Male & 16 & 0.932 & 22 & 15 & 0.248 & 21 & 16 & 0.617 & 19 & 18 & 0.413 & 18 & 19 & 0.666 & 15 & 22 & 0.742 \\
\hline Female & 19 & & 20 & 23 & & 22 & 21 & & 26 & 17 & & 23 & 20 & & 19 & 24 & \\
\hline Smoker & 14 & 0.136 & 18 & 7 & 0.019 & 17 & 8 & 0.085 & 15 & 10 & 0.649 & 15 & 10 & 0.291 & 12 & 13 & 0.502 \\
\hline Non smoker & 21 & & 24 & 31 & & 26 & 29 & & 30 & 25 & & 26 & 29 & & 22 & 33 & \\
\hline Alcohol drinker & 4 & 0.303 & 8 & 5 & 0.476 & 8 & 5 & 0.538 & 5 & 8 & 0.158 & 6 & 7 & 0.688 & 7 & 6 & 0.366 \\
\hline Non-alcohol drinker $\quad 36$ & 31 & & 34 & 33 & & 35 & 32 & & 40 & 27 & & 35 & 32 & & 27 & 40 & \\
\hline Alcohol mouthwash & 9 & 0.346 & 12 & 13 & 0.587 & 13 & 12 & 0.832 & 15 & 10 & 0.649 & 15 & 10 & 0.291 & 8 & 17 & 0.2 \\
\hline No alcohol mouthwash $\quad 29$ & 26 & & 30 & 25 & & 30 & 25 & & 30 & 25 & & 26 & 29 & & 26 & 29 & \\
\hline$>567 \mathrm{cfu} / \mathrm{ml}$ & 5 & 0.0797 & 13 & 6 & 0.112 & 12 & 7 & 0.346 & 12 & 7 & 0.487 & 8 & 11 & 0.361 & 12 & 7 & 0.037 \\
\hline$<567 \mathrm{cfu} / \mathrm{ml}$ & 30 & & 29 & 32 & & 31 & 30 & & 33 & 28 & & 33 & 28 & & 22 & 39 & \\
\hline Periodontal disease & 27 & 0.573 & 30 & 34 & 0.044 & 36 & 28 & 0.37 & 34 & 30 & 0.260 & 27 & 37 & 0.001 & 26 & 38 & 0.497 \\
\hline No periodontal disease & 8 & & 12 & 4 & & 7 & 9 & & 11 & 5 & & 14 & 2 & & 8 & 8 & \\
\hline Denture & 15 & 0.048 & 12 & 13 & 0.587 & 14 & 11 & 0.786 & 22 & 13 & 0.316 & 15 & 10 & 0.291 & 8 & 17 & 0.2 \\
\hline No denture & 20 & & 30 & 25 & & 29 & 26 & & 33 & 12 & & 26 & 29 & & 26 & 29 & \\
\hline C. albicans & 21 & $<0.0001$ & 39 & 24 & 0.002 & 27 & 36 & 0.038 & 46 & 17 & $<0.0001$ & 37 & 26 & 0.011 & 30 & 33 & 0.088 \\
\hline Non-albicans Candida & 23 & & 7 & 20 & & 18 & 9 & & 8 & 19 & & 8 & 19 & & 8 & 19 & \\
\hline C. albicans A & 21 & & 21 & 21 & & 25 & 17 & & 25 & 17 & & 19 & 23 & & 21 & 21 & \\
\hline C. albicans B & 12 & 0.436 & 9 & 11 & 0.553 & 9 & 11 & 0.310 & 7 & 13 & 0.116 & 13 & 7 & 0.218 & 8 & 12 & 0.436 \\
\hline C. albicans C & 0 & & 1 & 0 & & 0 & 1 & & 0 & 1 & & 1 & 0 & & 1 & 0 & \\
\hline
\end{tabular}

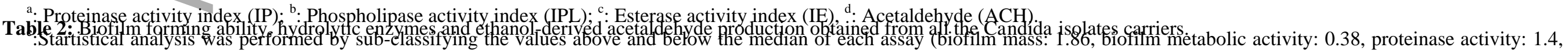

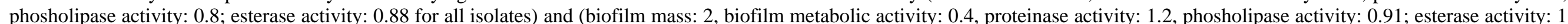
for C. albicans isolates). While for $\mathrm{ACH}$, values were sub-classified into above and below $40 \mu \mathrm{M}$. Chi square or Fisher's exact test were used to analyse the obtained data.

This article is protected by copyright. All rights reserved 
Table 3: Univariate and logistic regression analysis of possible risk effects of Candida virulence traits and some patients' factors in oral cancer.

\begin{tabular}{|c|c|c|c|c|c|c|}
\hline \multirow[b]{2}{*}{ Factor } & \multicolumn{3}{|c|}{ Univariate analysis } & \multicolumn{3}{|c|}{ Multivariate analysis } \\
\hline & OR & $95 \% \mathrm{CI}$ & $\mathrm{P}$ value & OR & $95 \% \mathrm{CI}$ & $\mathrm{P}$ value \\
\hline Low biofilm mass & 1.00 & & & 1.00 & & \\
\hline High biofilm mass & 2.72 & $1.08-6.87$ & $0.03^{*}$ & 2.37 & $0.64-8.75$ & 0.19 \\
\hline Low biofilm metabolic activity & 1.00 & & & 1.00 & & \\
\hline High biofilm metabolic activity & 7.5 & $2.73-20.58$ & $\mathrm{P}<0.001^{*}$ & 4.81 & $1.32-17.45$ & $0.01^{*}$ \\
\hline Low phospholipase activity & 1.00 & & & 1.00 & & \\
\hline High phospholipase activity & 4.33 & $1.65-11.36$ & $0.003^{*}$ & 5.50 & $1.34-22.45$ & $0.01^{*}$ \\
\hline Low proteinase activity & 1.00 & & & 1.00 & & \\
\hline High proteinase activity & 2.12 & $0.86-5.23$ & 0.1 & 1.97 & $0.55-7.07$ & 0.29 \\
\hline Low esterase activity & 1.00 & & & 1.00 & & \\
\hline
\end{tabular}




\begin{tabular}{lllllll} 
High esterase activity & 0.6 & $0.25-1.47$ & 0.52 & 0.52 & $0.15-1.78$ & 0.3 \\
Low Candida colonization & 1.00 & & & 1.00 & & \\
High Candida colonization & 3.58 & $1.19-10.72$ & $0.02^{*}$ & 2.84 & $0.54-14.81$ & 0.21 \\
Low Ethanol-derived ACH & 1.00 & & & 1.00 & & \\
High Ethanol-derived ACH & 3.33 & $1.32-8.43$ & $0.01^{*}$ & 1.91 & $0.57-6.41$ & 0.28 \\
Non-smoking & 1.00 & & & 1.00 & & \\
Smoking & 2.42 & $0.92-6.39$ & 0.07 & 1.72 & $0.4-7.31$ & 0.4 \\
No-alcohol drinking & 1.00 & & & 1.00 & & \\
Current/daily alcohol drinking & 5.25 & $1.32-20.9$ & $0.01^{*}$ & 14.97 & $2.02-110.91$ & $0.008^{*}$ \\
\hline
\end{tabular}

OR, odds ratio; $\mathrm{CI}$, confidence interval, $\mathrm{ACH}$, acetaldehyde.

*Statistically significant

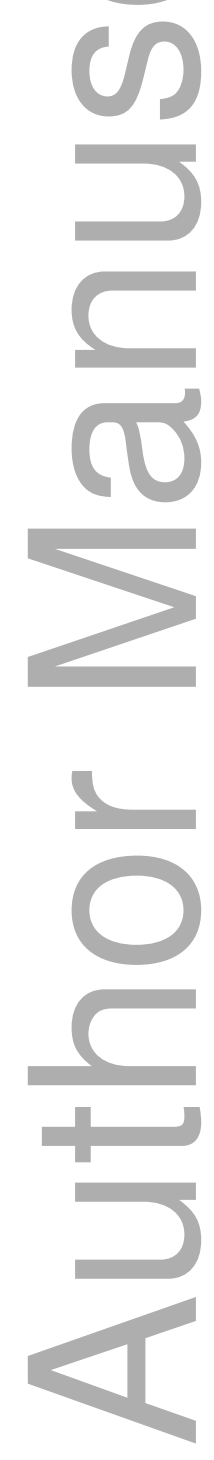




\section{Figure 1}
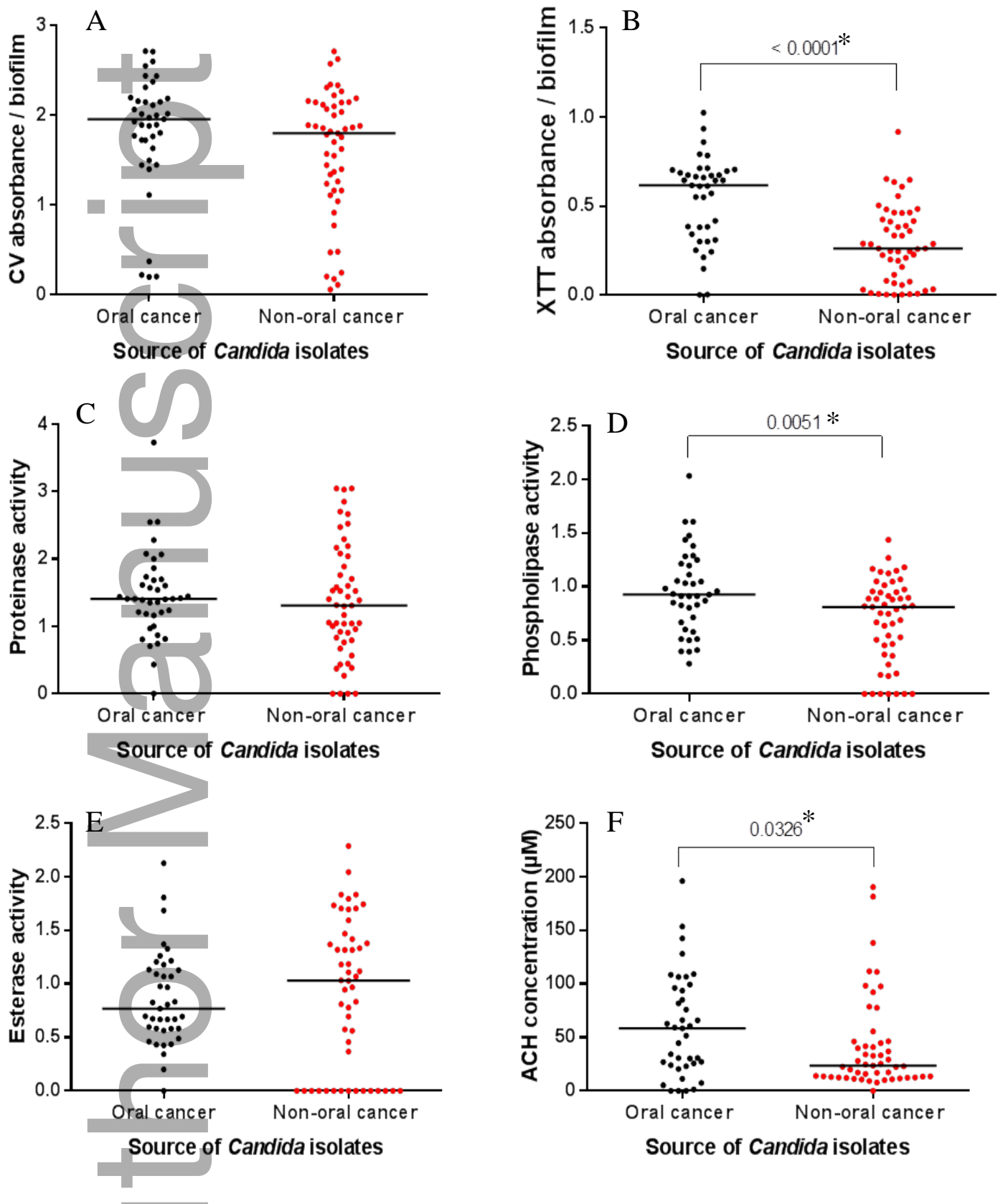

Figure 1: Comparison of biofilm forming ability (A and B), hydrolytic enzymes (C, D and E) and ethanolderived acetaldehyde production capability $(\mathrm{F})$ of all Candida isolated from oral cancer and non-oral cancer patients. Each dot represents the mean of measurements performed in triplicate on two separate occasions and the horizontal line represents the median value of each subgroup.

*P value by Mann-Whitney analysis; CV: biofilm mass as assessed by crystal violet assay; XTT: biofilm metabolic activity as assessed by XTT salt reduction assay; ACH: acteylaldehyde produced from incubation of yeast with $11 \mathrm{mM}$ ethanol. 


\section{Figure 2}
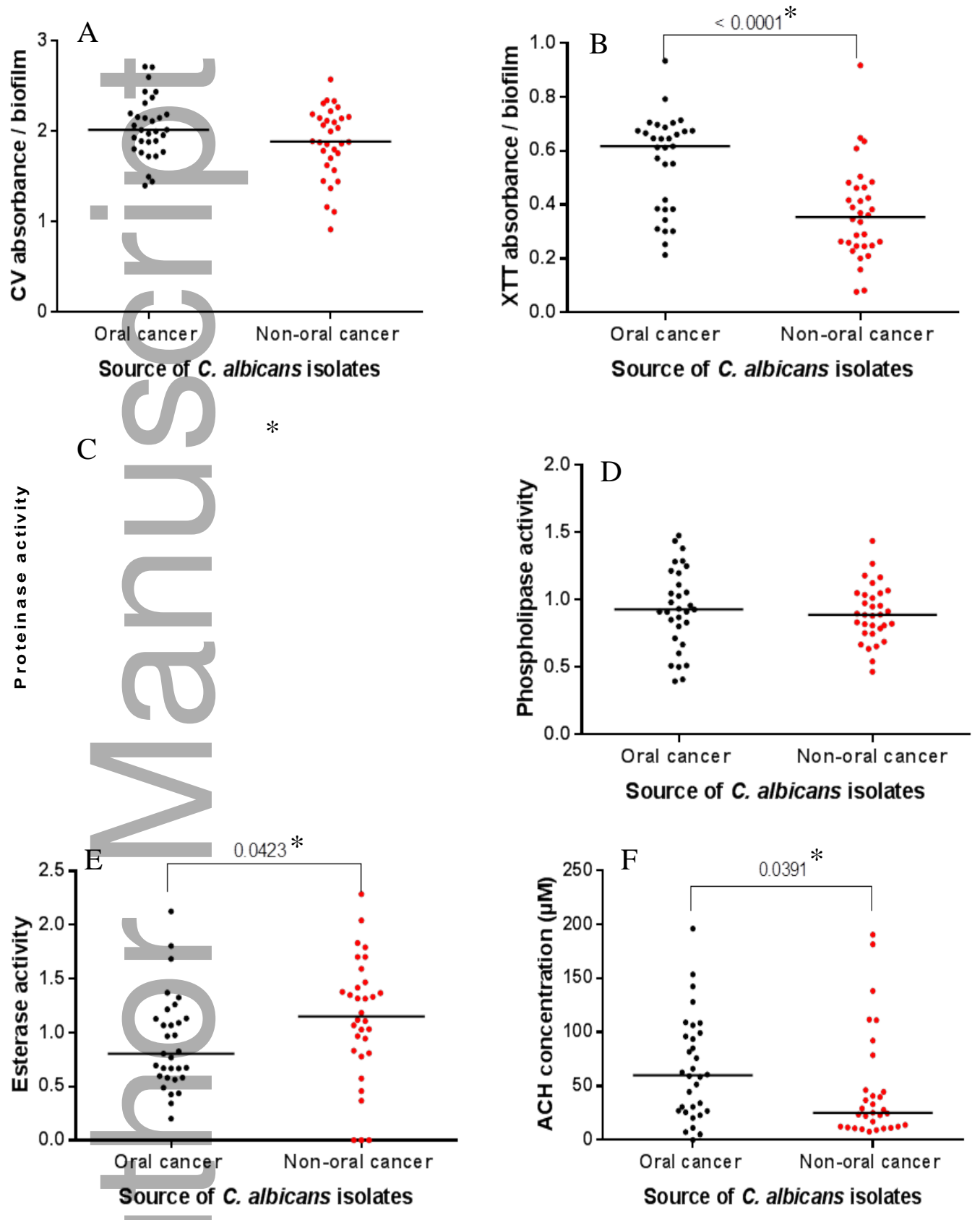

Figure 2: Comparison of biofilm forming ability (A and B), hydrolytic enzymes (C, D and E) and ethanolderived acetaldehyde production capability $(\mathrm{F})$ of $C$. albicans yeasts isolated from oral cancer and non-oral cancer patients. Each dot represents the mean of measurements performed in triplicate on two separate occasions and the horizontal line represents the median value of each subgroup.

*P value by Mann-Whitney analysis; CV: biofilm mass as assessed by crystal violet assay; XTT: biofilm metabolic activity as assessed by XTT salt reduction assay; ACH: acteylaldehyde produced from incubation of yeast with $11 \mathrm{mM}$ ethanol. 


\section{Figure 3}
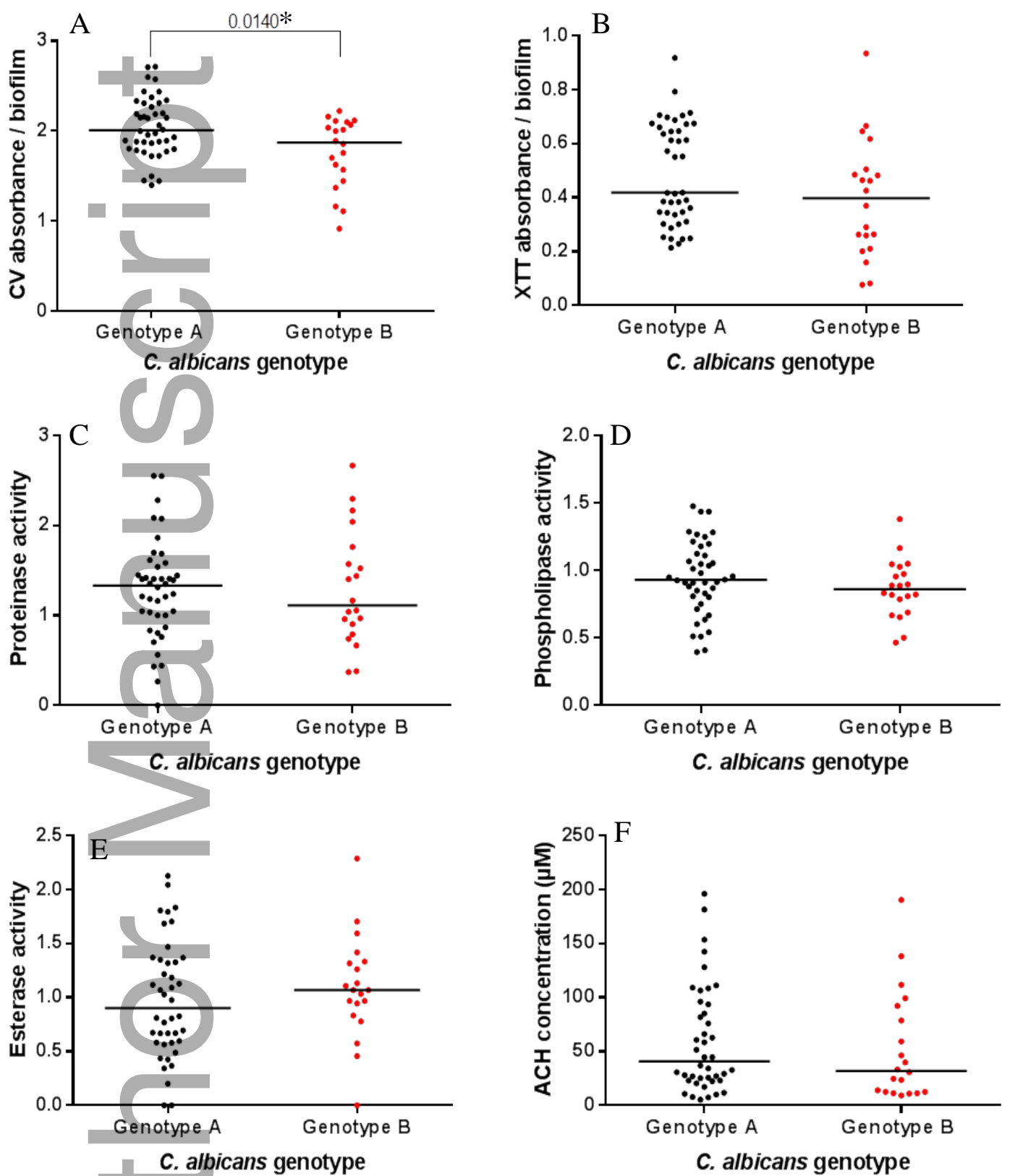

Figure 3: Comparison of biofilm forming ability (A and B), hydrolytic enzymes (C, D and E) and ethanolderived acetaldehyde production capability $(\mathrm{F})$ of all $C$. albicans genotypes isolated from oral cancer and nonoral cancer patients. Each dot represents the mean of measurements performed in triplicate on two separate occasions and the horizontal line represents the median value of each subgroup.

*P value by Mann-Whitney analysis; CV: biofilm mass as assessed by crystal violet assay; XTT: biofilm metabolic activity as assessed by XTT salt reduction assay; ACH: acteylaldehyde produced from incubation of yeast with $11 \mathrm{mM}$ ethanol. 


\section{University Library}

\section{- M M N E R VA A gateway to Melbourne's research publications}

Minerva Access is the Institutional Repository of The University of Melbourne

\section{Author/s:}

Alnuaimi, AD;Ramdzan, AN;Wiesenfeld, D;O'Brien-Simpson, NM;Kolev, SD;Reynolds, EC;McCullough, MJ

Title:

Candida virulence and ethanol-derived acetaldehyde production in oral cancer and noncancer subjects

Date:

2016-11-01

Citation:

Alnuaimi, A. D., Ramdzan, A. N., Wiesenfeld, D., O'Brien-Simpson, N. M., Kolev, S. D., Reynolds, E. C. \& McCullough, M. J. (2016). Candida virulence and ethanol-derived acetaldehyde production in oral cancer and non-cancer subjects. ORAL DISEASES, 22 (8), pp.805-814. https://doi.org/10.1111/odi.12565.

Persistent Link:

http://hdl.handle.net/11343/291717 